\title{
LA LÓGICA ESTÉTICO-SACRAMENTAL DE LA FIESTA RELIGIOSA
}

The aisthetic-sacramental logic of religious feast

\author{
FEDERICO AGUIRRE \\ Pontificia Universidad Católica de Chile (Chile). \\ Facultad de Teología. Centro de Estudios de la Religión. \\ federico.aguirre@uc.cl
}

Resumen

En el presente artículo se busca describir el rol fundamental que juega la experiencia estética en los procesos de significación de lo que se suele denominar "religión popular". Para esta labor, tomamos como objeto de estudio la fiesta religiosa que, junto con hacer referencia a una determinada realidad empírica, nos provee de dos mediaciones conceptuales para el desarrollo de nuestro análisis: la fiesta y la imagen. De este modo, después de contextualizar nuestra reflexión en el marco de los estudios culturales y la estética, procedemos a definir la lógica estético-sacramental de la fiesta religiosa a partir de los conceptos de "fiesta" e "imagen", abordados desde el enfoque de la New Material Culture.

Palabras clave: Arte; teología; religión popular; fiesta religiosa; imagen de culto.

Abstract

The aim of this article is to describe the fundamental role of the aesthetic experience in the processes of signification of what is usually called "popular religion". In order to achieve this, we define as the object of our study the religious feast, which, apart from referring to a concrete empirical reality, provides us with two conceptual mediations for our analysis: feast and image. Thus, following a contextualization of our reflection on the field of cultural studies and aesthetics, we proceed to define the aesthetic-sacramental logic of the religious feast on the basis of the concepts "feast" and "image", from the perspective of the New Material Culture approach.

Key words: Art; theology; popular religion; religious feast; cult image.

\section{INTRODUCCIÓN}

El estudio que presentaremos a continuación se inscribe en la última etapa de un proyecto de investigación que comenzó el 2017. Nuestra investigación surge a partir de la constatación del rol fundamental que asume la experiencia estética en el contexto de lo que se suele denominar "religión popular". En el proceso de revisión bibliográfica que precedió el comienzo de nuestra investigación, no obstante, descubrimos que este término ha asumido sobre todo una connotación negativa, contraponiéndose a lo que se podría denominar la "religión oficial" (Aguirre, 2020a, pp. 170-176). Incluso interpretada como una "contracultura" (Morandé, 1986), es decir, como una alternativa plausible respecto de la cultura dominante, la "religión popular" termina la mayoría de las veces relegada al ámbito de lo pintoresco y lo folclórico. 
Este modelo de los dos niveles (Brown, 2018), que hunde sus raíces en la filosofía de la religión desarrollada durante la llustración, ha dado lugar a esquemas de interpretación binarios, en los que se suele diferenciar de manera taxativa entre lo culto y lo popular, lo institucional y lo espontáneo, lo racional y lo simbólico, lo litúrgico y lo ritual. Sin desconocer la tensión existente en los procesos culturales de las sociedades coloniales, consideramos que este tipo de interpretaciones, además de esencialistas, no se corresponden con la realidad híbrida de nuestro continente, donde cada día se hace más complejo distinguir entre lo propio -lo indígena- y lo ajeno -lo occidental-, más allá de una determinada postura política (García Canclini, 2001).

Para la teología latinoamericana, la "religión popular" se ha constituido en un tema fundamental, "un lugar teológico al que debemos prestar atención, en particular a la hora de pensar la nueva evangelización" $(E G, 126)$. No obstante, el modelo de los dos niveles también ha impregnado la reflexión de la teología, generando una suerte de hiato entre la vida teologal de los pueblos latinoamericanos y la ciencia teológica. En este sentido, la negatividad -o la positividad contracultural- del "cristianismo popular" contrasta con el hecho de que la mayor parte de la población latinoamericana que se declara cristiana ejerce su pertenencia a la Iglesia "popularmente" . La reflexión teológica ha asumido, en mayor o menor medida, la contraposición entre el carácter ritual y simbólico del catolicismo popular respecto del modo litúrgico e intelectual en que se expresaría el catolicismo oficial (Aguirre, 2020a, pp. 172-176).

Esta esquematización, de manera implícita o explícita, ha tenido un profundo impacto en la valoración teológica de las prácticas en las que se encarna la fe de los pueblos latinoamericanos, desdibujando una cuestión teológico-fundamental que subyace al ejercicio hermenéutico de la teología: la definición del estatuto epistemológico del modo "estético-sacramental" en que esta fe se significa. Dicho de otro modo, si en realidad postulamos que las imágenes, las animitas, las fiestas, los bailes religiosos, o las procesiones, han dado lugar a una vida teologal propia $(E G, 125)$, se hace imprescindible para la ciencia teológica definir de qué modo y en qué sentido estas prácticas se constituyen en instancias de revelación.

Por consiguiente, más allá de la contraposición con otras formas culturales que ha asumido el cristianismo - que son muchas y diversas-, el cristianismo latinoamericano tiene formas culturales propias, las que han originado modos propios de significar la

\footnotetext{
${ }^{1}$ El proceso de valoración teológica de la "religiosidad popular", el “catolicismo popular" o la "piedad popular" comienza en los años 60 del siglo pasado, y, sin lugar a dudas, ha presentado diversos desarrollos y connotaciones. No obstante, nos parece que la negatividad es intrínseca a los términos en cuestión, convirtiéndose en un eufemismo. Algunos hitos en la definición de estos tópicos: el Documento Conclusivo de Medellín (1968), la Exhortación Apostólica de Pablo VIEvangelii Nuntiandi (1976), el Documento Conclusivo de Puebla (1979), el Documento Directorio sobre la piedad popular y la liturgia (2002), el Documento Conclusivo de Aparecida (2007), y la Exhortación Apostólica de Francisco Evangelii Gaudium (2013).

66 | Alpha № 53 (Diciembre 2021) PÁGS. 65-88. ISSN 07 16-4254
} 
experiencia de fe ${ }^{2}$. En nuestra opinión, la dificultad para abordar esta especificidad cultural se ha debido en gran medida a la indefinición de un determinado referente empírico, aplicándose el adjetivo de popular a una masa indeterminada de objetos y prácticas religiosas (desde el rezo del rosario hasta los bailes religiosos).

De este modo, la primera etapa de nuestra investigación consistió en la provisión de una base empírica para problematizar los modos de significar que entran en juego en este contexto, y así, después, proceder a un intento de valoración teológica. Nuestro trabajo de campo se enfocó en la relación que establecen las personas con las imágenes durante la celebración de tres fiestas religiosas que animan la vida social y cultural de nuestro país ${ }^{3}$. En este contexto, la imagen aparece como el "objeto focal" (Morgan, 2018) en torno al que se articula todo el evento festivo y en el que se condensa el flujo de lo sagrado.

Para realizar el análisis de la información de campo, procedimos a la confección de una matriz comparativa en la que, por una parte, describimos la taxonomía de cada fiesta y, por otra, las situaciones concretas de interacción entre las imágenes y los fieles. En los tres casos estudiados, si bien existe una clara conciencia de que se trata de un objeto inanimado, los actores se refieren a la imagen como a una "persona", reconociendo en ella una "agencia" (Gell, 2016) capaz de intervenir las relaciones de la comunidad, cambiar sus vidas y, en definitiva, capaz de originar complejos procesos de significación que son inseparables de la condición material de la imagen ${ }^{4}$.

Esta realidad descrita por los actores que participan en las fiestas estudiadas desafía los esquemas semióticos tradicionales, que suelen distinguir de forma categórica entre la condición material del símbolo y su estructura de significado, desmaterializando los objetos en busca de un contenido conceptual que está más allá de ellos. Por esta razón, como marco teórico de nuestra investigación, hemos optado por el enfoque de la denominada New Material Culture, que destaca la capacidad performativa propia de los objetos y el rol que

\footnotetext{
2 A este respecto cabe destacar el enfoque desarrollado por las teologías latinoamericanas "culturalistas"(Johansson 1990: 223-251), entre cuyos aportes destacan los trabajos de Alberto Methol, Lucio Gera o Rafael Tello. Este enfoque, que surge de la eclesiología cultural del Concilio Vaticano II, se fragua en torno al encuentro de Puebla (1979), y ha influenciado de manera decisiva el pensamiento de Francisco, quien destaca que sin cultura no hay Iglesia y que ninguna cultura es más idónea que otra para el anuncio del Evangelio (véase $E G$ 115-118).

${ }^{3}$ Las fiestas estudiadas son la Virgen de la Tirana, en el norte, San Pedro, en Caleta Portales, y el Nazareno de Caguach, en Chiloé. Sobre los resultados del trabajo de campo de nuestra investigación véase Aguirre 2020a , p. 202, donde se justifica el carácter ejemplar que asume la fiesta religiosa como referente empírico: "La fiesta religiosa, en definitiva, muestra un equilibrio dinámico de todas aquellas tensiones que constituyen el fenómeno de la religión popular en nuestros días y visibiliza de manera paradigmática su modo de ser festivo e icónico". 4 "Por ejemplo, algunos creyentes esperan que besar un icono sagrado suscita la agencia de la imagen de manera que les alivie una enfermedad o la pobreza [...] Cuando hay que tocar las imágenes, en vez de solo mirarlas, existe agencia en el índice físico, lo que no significa que se excluya la agencia del prototipo en estos casos" Gell 2016: 65 .
} 
juega esta en la configuración del significado ${ }^{5}$. Como quisiéramos establecer en lo que sigue, este tipo de prácticas en torno a la imagen en el contexto de las fiestas religiosas cristianas dan cuenta de una "lógica estético-sacramental", es decir, un modo de significar que posee un estatuto epistemológico propio, inseparable de la experiencia sensible, y mediante ello los pueblos de Latinoamérica significan y realizan su participación sacramental en el misterio de Dios $(S C, 7)$.

\section{LA OTRA LÓGICA}

A partir de la segunda mitad del siglo XX, diversos autores latinoamericanos han elaborado propuestas de interpretación para el ethos o modo específico de ser, pensar y actuar de los pueblos latinoamericanos, y en todas ellas, de manera más o menos explícita, se hace referencia a la denominada "religión popular" y al significativo rol que esta juega en la consolidación de la modernidad latinoamericana. Pensemos en la obra de autores como Octavio Paz (El laberinto de la soledad, 1950), Rodolfo Kusch (Geocultura del hombre americano, 1976), Enrique Dussel (Praxis latinoamericana y filosofia de la liberación, 1983), Néstor García Canclini (Culturas híbridas. Estrategias para entrar y salir de la modernidad, 1990), o Bolívar Echeverría (La modernidad de lo barroco 1998) $)^{6}$. También es importante destacar que esta enérgica corriente de pensamiento latinoamericano del siglo pasado estuvo muy influenciada por la acción pastoral de la Iglesia, agente fundamental en los procesos de transformación socioculturales en Latinoamérica desde los años 30 del siglo pasado.

Además del factor "religioso popular", llama la atención en la obra de estos autores la conciencia clara de que pensar la cultura significa hacerse cargo, en el fondo, de una cuestión epistemológica, sobre todo en el contexto de la modernidad tardía. En otras palabras: si en verdad queremos comprender y proyectar el modo de ser de una determinada comunidad, debemos problematizar su modo de significar. Es en este sentido que Cristián Parker (1994) habla de la "otra lógica" de la cultura latinoamericana,

\footnotetext{
${ }^{5}$ Este movimiento surge a partir de los años 90 del siglo pasado, en particular desde las ciencias sociales anglosajonas, y ha tenido un fuerte impacto en la discusión estética de los últimos años y en el desarrollo de los estudios de la religión. Además de los autores que citamos en este trabajo, Alfred Gell (2016) y David Morgan (2018), la revista Journal of Material Culture, fundada en 1996, se ha constituido en una importante plataforma de difusión de este movimiento, así como la revista Material Religion, lanzada en el año 2005. Respecto al empleo de esta teoría en el contexto de nuestra investigación véase Aguirre, p. 2020a, pp. 176-181.

6 “Todos ellos son esfuerzos hermenéuticos para pensar una cosmovisión americana hemiderna, no-occidental, que está atravesada desde una perspectiva semántica por categorías e influencias culturales de Occidente, que recoge las tradiciones ancestrales precolombinas, que reclama pensarse en categorías propias todavía en gestación y búsqueda (por ello tributarias de estructuras categoriales que nos vienen de la tradición occidental), pero que en su 'síntesis vital', en su sincretismo religioso y en su mestizaje cultural nunca ha sido por completo occidental y que ya desde la conquista ha dejado de ser enteramente indígena" (Parker 1994, p. 371).

68 | Alpha No 53 (Diciembre 2021) PÁGS. 65-88. ISSN 07 16-4254
} 
caracterizándola como "simbólica", "dramática” y "sapiencial”, subrayando su principio matérico-sensorial y enfatizando que "no es ciertamente una antilógica o un estado primitivo de la facultad de razonamiento -y en este sentido no es prelógica, para usar la expresión de Lévy-Bruhl (1977)-, sino que representa el uso de la razón bajo otro sistema mucho más empírico y simbólico a la vez, mucho más sapiencial y dialéctico que cartesiano y positivista" (370)

Ahora bien, en alguna medida, la caracterización de Parker incurre en la misma dinámica binaria (culto-popular, simbólico-conceptual, sincrético-occidental) que hemos planteado como problema y que, en nuestra opinión, conduce a valoraciones en extremo generales $^{8}$. El principal vicio de este tipo de conceptualización es el solapamiento de la heterogeneidad que caracteriza al fenómeno en cuestión, heterogeneidad que, sin embargo, todos los autores destacan como elemento constitutivo; así, el mismo Parker subraya la necesidad de vincular la reflexión teórica a un referente empírico concreto (p. 382). Por esta razón, en el contexto de nuestra investigación, hemos enfatizado la condición paradigmática de la fiesta religiosa, la que, por una parte, hace referencia a una determinada realidad empírica, pero, a su vez, nos provee dos mediaciones conceptuales para definir la lógica estético-sacramental que allí entra en juego: la fiesta y la imagen ${ }^{9}$.

Diversos autores han tratado el tema de la fiesta como un componente fundamental de la vida social ${ }^{10}$. El sociólogo francés Françoise-André Isambert (1982) indica que el auge de los estudios acerca de fiesta en Europa a partir de la década de los

\footnotetext{
7 Parker habla también de un pensamiento "sincrético", opuesto al pensamiento ilustrado: "Frente al pensamiento 'culto', vehiculado por un lenguaje conceptual y abstracto, denotativo por una vasta red lexical y una retórica inflada, característica de toda cultura 'letrada', rigurosa en el recorte semiótico de la realidad en forma normativa y represiva, el pensamiento sincrético popular se expresa por vía de imágenes y símbolos, por medio de la expresión oral, con una retórica corta, de pocas palabras pero de mucha expresividad, recargada de connotaciones propias del léxico popular (masivo, sensual, picaresco, dramático, lúdico) y de una red gestual que constituye su soporte significante en el mismo título que las palabras" (p. 373).

${ }^{8}$ Con todo, Parker es consciente del peligro de la generalización: "No es que exista un pensamiento popular universal para todo el continente latinoamericano; es que existen procesos de pensamiento análogos en correspondencia con situaciones estructurales e históricas igualmente análogas que dan origen a un estilo determinado, a un tipo particular de mentalidad" (p. 376).

9 "En este sentido, más que de símbolos que significan otra cosa que no está en ellos y en torno a los que se desarrolla una ritualidad indefinida y marginal, nos parece más adecuado hablar de imágenes que detentan y provocan agencia: actos concretos que se articulan en complejos acontecimientos festivos, los cuales poseen una estructura dramático-litúrgica, constituyen fuertes tejidos sociales, culturales y eclesiales, y cuyas formas discursivas — su lenguaje o $\lambda$ ójos — son inseparables de una performatividad que se da en lo material y lo corpóreo. De acuerdo con esto, planteamos las categorías de 'fiesta' e 'imagen' como más idóneas que las de 'rito' y 'símbolo' para abordar la lógica estética de la fe popular, habida cuenta que nuestra hipótesis de trabajo otorga un rol fundamental a las expresiones materiales del fenómeno y se basa en el análisis de su especificidad sensible" (Aguirre 2020 , pp. 228-229).

${ }^{10}$ Destacamos la obra de Mijail Bajtín, Joseph Pieper y Uwe Schultz; en Chile, en particular, los trabajos de Isabel Cruz, Fidel Sepúlveda, Maximiliano Salinas, o Rodrigo Moulián, entre otros/as.
} 
70 del siglo pasado está muy relacionado con el descubrimiento del fenómeno de la "religión popular" en la misma época, notando, sin embargo, un interés más bien folclórico. En América Latina, por el contrario, la fiesta, con su naturaleza ritual (Sepúlveda 2000), se plantea como una auténtica "utopía social" moderna (Salinas 2006), que pervive hasta la actualidad y cuya multidimensionalidad (ética, estética y económica) se sintetiza bajo el término de "lo barroco" (Echeverría 2011, Cruz 1995 y Cullen 1981). En este sentido, como destaca Isabel Cruz (1995), en el contexto de la cultura latinoamericana, el Barroco no hace referencia a un mero estilo, sino que se trataría de un "concepto de época", cuyo alcance de proyecto cultural sería análogo al del término "modernidad" en el imaginario de las Vanguardias históricas ${ }^{11}$.

En el sugerente trabajo de Bolívar Echeverría (2011), influenciado por la reflexión de Walter Benjamin, se platea que el Barroco da lugar a una "estetización" de la vida (pp. 185-198), uno de cuyos principales dispositivos es justamente la fiesta religiosa (pp. 196-197). Es necesario advertir que en el enfoque de Echeverría -como en el de otros/as autores/as que reflexionan respecto de la naturaleza estética de la fiesta- lo estético no hace referencia a un canon de belleza, a una suerte de norma para la producción de objetos calificados como "obras de arte", sino a un modo de conocer y actuar que, no obstante, se encuentra enraizado en la experiencia sensible y se significa sobre todo mediante expresiones artísticas (poesía, teatro, música, imágenes, pero también la comida y la bebida):

La "exagerada" estetización barroca de la vida cotidiana, "que vuelve fluidos los límites entre el mundo real y el mundo de la ilusión", no debe ser vista como algo que es así porque no alcanza a ser de otro modo, como el subproducto del fracaso en una construcción realista del mundo, sino como algo que es así porque pretende ser así: como una estrategia propia y diferente de construcción de mundo (p. 195) ${ }^{12}$.

Como subrayan Isabel Cruz (1995) y Luz Ángela Martínez (2011), esta dimensión estética de la existencia se fundamenta en una auténtica metafísica de la apariencia, en la que actos corporales como mirar, tocar, oler, comer o beber, que de manera habitual se asocia a la irracionalidad, lo corruptible, y lo degradante, constituyen la fuente primordial

\footnotetext{
${ }^{11}$ Para una reseña crítica de esta concepción del Barroco véase Espinosa (2012).

${ }^{12}$ Véase tb.: "En este sentido el carnaval no era una forma artística de espectáculo teatral, sino más bien una forma concreta de la vida misma, que no era solo representada sobre un escenario, sino vivida en la duración del carnaval." (Bajtín 2003: 13) y "El barroco ofrece al respecto un repertorio inagotable, porque fue maestro en la transformación de la vida en teatro y del hombre en actor. Esa cultura había adquirido una precisa conciencia de la capacidad de metamorfosis del hombre y pleno dominio de las artes de la representación" (Cruz, 1995, p. 20). Esta "estetización" de la vida, junto con las otras dimensiones que comporta el Barroco como sistema cultural (economía, ética, política), habría pervivido en las expresiones contemporáneas de la denominada "religión popular" (Cruz, 1995, pp. 63-68).
}

70 | Alpha № 53 (Diciembre 2021) PÁGS. 65-88. ISSN 07 16-4254 
de un conocimiento siempre enraizado en la experiencia sensible y que, por tanto, no termina nunca confinándose en el ámbito de la abstracción y las leyes universales ${ }^{13}$. En este sentido, destaca Echeverría (2011, pp. 194-195), en el mundo barroco el valor de uso -es decir, el valor a veces inestimable que se asigna a los objetos a partir de la experienciapredomina respecto del valor de cambio, que convierte los objetos en mercancías y los supedita a la abstracción de la moneda ${ }^{14}$. Así, apreciados desde su valor de uso, "los objetos mantenían su materialidad y su pluralidad, y la vida su riqueza en lugar de subordinarse a la tiranía de la lógica abstracta de la equivalencia" (Espinosa, 2012, pp. 72-73).

En este contexto, muchas de las producciones que solemos catalogar como "obras de arte", así como otras producciones que quedarían fuera de esta catalogación o serían caracterizadas como "artes menores", asumen un rol fundamental en las dinámicas de significación de la realidad, determinando los procesos de producción y recepción de la obra y desperfilando las distinciones y categorizaciones de la estética normativa, tales como copia-original, ficticio-real, bello-feo, culto-popular, etc. De este modo, la obra de arte no se restringe a un espacio de exhibición o a un público especializado, sino que se inserta en una red de objetos y prácticas comunes que poseen una misma naturaleza "estética" - matérico-sensorial- de la que todos y todas participan. A su vez, lo que hace el artista no comporta mayor genialidad que lo que hace el hombre común y corriente, que es capaz de darle vida a la obra con su propia vida:

El artista propiamente dicho sería, así, alguien que es capaz -por su disposición excepcional, por la técnica que domina- de proporcionar oportunidades de experiencia estética para la comunidad; de ampliar la medida privada (espacial, temporal, semiótica) en que todos alcanzan a estetizar sus vidas singulares: en que todos componen las condiciones necesarias para la integración de la plenitud imaginaria del mundo en el terreno de la experiencia ordinaria y, al hacerlo, recomponen su vida cotidiana, en mayor o menor medida, en torno a ese momento de "interferencia" del tiempo extraordinario en el tiempo de la rutina (Echeverría, 2011, p. 192).

\section{LA LÓGICA ESTÉTICA}

\footnotetext{
${ }^{13}$ Bajtín (2003) habla de un principio matérico-sensorial de la fiesta: "El principio material y corporal es percibido como universal y popular, y como tal, se opone a toda separación de las raíces materiales y corporales del mundo, a todo aislamiento y confinamiento en sí mismo, a todo carácter ideal abstracto o intento de expresión separado e independiente de la tierra y el cuerpo" (p. 24).

${ }^{14}$ Véase tb.: "los gastos en artes, juegos y espectáculos no pueden ser considerados 'gastos improductivos' [...] Se trata, por el contrario, de 'consumo puro', que es también consumación, vale decir, es llevar a cabo el gasto en todas sus consecuencias y en toda su plenitud, el cual a su vez conduce a la gratuidad y a la generosidad; a la entrega, y al don." (Cruz, 1995, p. 33).
} 
Es oportuno recordar que el término "estética", entendido como campo disciplinar de la filosofía, se acuña en el siglo XVIII precisamente a partir de un debate en torno a la validez epistemológica de la experiencia sensible. La filosofía hermenéutica, junto con otras corrientes filosóficas contemporáneas, ha destacado la dimensión cognitiva de la experiencia estética y su vinculación con la experiencia de lo sagrado, retrotrayendo el debate a la teoría estética de Aristóteles. Destacamos a este respecto los trabajos de Hans Georg Gadamer (1999 y 1991) y Paul Ricoeur (2004). Así, tomando como punto de partida el problema de la inverosimilitud del arte en el mundo moderno, Gadamer desarrolla una crítica a la estética normativa que se instaura a partir de la Ilustración, pero cuyos fundamentos se encuentran en el largo proceso de recepción e interpretación occidental de la filosofía griega (1999, pp. 31-222).

La crítica de Gadamer apunta a la subestimación de la dimensión cognitiva de la experiencia estética que tiene lugar a partir de la Ilustración -logica facultatis inferioris-, confinándola al ámbito de lo subjetivo, lo ficticio, lo carente de validez universal, situación que se debería, junto a otros factores, al proceso de secularización del arte. Por consiguiente, Gadamer, asumiendo la crítica moderna, intentará redefinir para nuestra época el estatuto epistemológico y el sentido ritual del arte, remitiéndose a la mímesis aristotélica y asociando este concepto a la experiencia del juego y lo sagrado como elementos fundamentales de la experiencia estética:

La teoría antigua del arte, según la cual a todo arte le subyace el concepto de la mímesis, de la imitación, partía también evidentemente del juego que, como danza, es la representación de lo divino. Sin embargo, el concepto de imitación solo alcanza a describir el juego del arte si se mantiene presente el sentido cognitivo que existe en la imitación [...] El que imita algo, hace que aparezca lo que él conoce y tal como lo conoce. El niño pequeño empieza a jugar imitando, y lo hace poniendo en acción lo que conoce y poniéndose así en acción a sí mismo. La misma ilusión con que los niños se disfrazan, a la que apela ya Aristóteles, no pretende ser un ocultarse, un aparentar algo para ser adivinado y reconocido por detrás de ello, sino al contrario, se trata de representar de manera que haya solo lo representado. El niño no quiere ser reconocido a ningún precio por detrás de su disfraz. No debe haber más que lo que él representa y si se trata de adivinar algo, es qué "es" esa representación (Gadamer, 1999, pp. 157-158) ${ }^{15}$

\footnotetext{
15 Gell (2016) va todavía más allá: "percibir -internalizar-, es imitar, y así nos convertimos en lo que percibimos; lo producimos" (p. 65) y "Ver (o saber) es llenarse sensorialmente con lo percibido, someterse a ello, reflejarlo y, por tanto, imitarlo con el cuerpo" (p. 142). En este mismo sentido, la mímesis, según

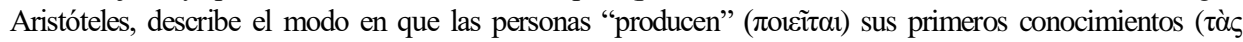
$\mu \alpha \theta \tilde{\eta} \sigma \varepsilon ı \zeta)$ (Poética, 1448b).
}

72 | AlPha № 53 (Diciembre 2021) PÁGS. 65-88. ISSN 07 16-4254 
Según Gadamer, en nuestra época se ha cultivado una suerte de idolatría de las ciencias positivas que ha ensombrecido otras dimensiones cognitivas de la existencia, como son la experiencia del arte y la experiencia de lo sagrado. Ambas experiencias estarían interconectadas y darían lugar a un tipo de conocimiento "mimético", que se diferencia respecto del conocimiento "científico", pero que tiene una validez epistemológica propia y una incidencia fundamental en la vida social. Ricoeur, por su parte, ahonda en el análisis del concepto aristotélico de mímesis, subrayando sus implicancias éticas y destacando que, al menos en la Poética, Aristóteles no se preocupa tanto de establecer un canon literario como de explicar el funcionamiento ritual y político de la obra de arte -en particular la tragedia-, cuya principal función, más allá de agradar o entretener, es sobre todo incidir en el orden moral y social ${ }^{16}$.

La filosofía hermenéutica-junto con otras corrientes de raigambre fenomenológica o analítica como la estética de la recepción o la estética pragmatista- formula lo que podríamos llamar una "estética descriptiva", que problematiza la función cognitiva del arte, en contraste con las "estéticas normativas" de cuño intelectualista, que apuntan más bien a la diferenciación del arte como un quehacer erudito y a la definición de un canon ${ }^{17}$. Una reseña detallada de esta discusión no es el objetivo del presente artículo. En este sentido, nuestro principal interés es poner de relieve que lo que hemos denominado "lógica estéticosacramental" ha sido objeto de reflexión tanto en el debate referente a la cultura latinoamericana como en la discusión estética contemporánea, y que en ambos casos el calificativo de "estético" apunta a la descripción de la dimensión epistemológica del arte más que a una definición normativa de algo así como su esencia.

En nuestra opinión, en esta misma línea descriptiva se inscriben los aportes de la denominada New Material Culture, enfoque que hemos adoptado para el desarrollo de la investigación que presentamos aquí. En este sentido, la ácida crítica de la New Material Culture al concepto de "estética" apunta, según nuestro punto de vista, a lo que hemos

\footnotetext{
16 "Se puede intentar negar el problema mismo y considerar como no pertinente la cuestión del impacto de la literatura sobre la experiencia cotidiana. Pero entonces, por una parte, se ratifica paradójicamente el positivismo que en general se está combatiendo, a saber: el prejuicio de que solo es real el dato que puede observarse de manera empírica y describirse desde una perspectiva científica, y por otra, se encierra la literatura en un mundo en sí y se rompe la punta subversiva que lanza contra el orden moral y social. Se olvida que la ficción es sobre todo lo que hace del lenguaje ese supremo peligro del que Walter Benjamin, tras Hölderlin, habla con temor y admiración" (Ricoeur, p. 2004, p. 151).

${ }^{17}$ Otro ejemplo interesante de "estética descriptiva" es el enfoque desarrollado por los denominados "estudios de la performance", que ponen de relieve la disolución de los límites del arte y su ingreso en el ámbito de la praxis social y política (véase Tylor-Fuentes, 2011). Esta misma distinción entre naturaleza normativa y descriptiva cabría hacer entre la estética teológica de Hans Urs Von Balthasar, por ejemplo, que en definitiva apunta a la fundamentación de una metafísica, respecto de una "teología del arte", que busca retrotraer la reflexión al ámbito de la sensación, la experiencia y la realización (Bergmann, 2014). Sobre la distinción entre "estética normativa" y "estética descriptiva" véase Tatarkiewicz (2016, pp. 19-30).

AlPHA No 53 (DiciEMBRE 2021) PÁGS. 65-88. ISSN 07 16-4254| 73
} 
llamado "estética normativa"18. Así, en nuestra investigación, cuando hablamos de "lógica estético-sacramental" no nos referimos a una suerte de principio universal o a una ortodoxia religiosa identificable en todas las fiestas religiosas, sino a un modo de significar que allí se manifiesta y que ha sido problematizado desde los orígenes mismos de la filosofía ${ }^{19}$.

Ahora bien, a diferencia de la hermenéutica y otras corrientes filosóficas que se centran en un desarrollo más bien teórico, el enfoque de la New Material Culture avanza en una dirección fundamental para nuestra investigación: problematiza de manera consistente la especificidad matérico-sensorial y el carácter performativo de la experiencia estética-que es lo que nosotros queremos denotar con los adjetivos "estéticosacramental" -, llamando la atención sobre el peligro que comporta una reflexión teórica que abandona demasiado rápido su referente empírico (Gell, 2016, p. 34) ${ }^{20}$. Asimismo, si bien la teoría hermenéutica problematiza la dimensión performativa de toda forma de arte mediante conceptos como mímesis, "representación" (Darstellung) o "refiguración", su análisis se centra en particular en la literatura y el proceso interpretativo que desencadena en las personas.

Lo novedoso del enfoque de la New Material Culture es el énfasis en la performatividad propia de la obra desde su condición material, constituyéndose esta, aparte del significado que los receptores le atribuyan, en agente social y, en definitiva, en productora de significado ${ }^{21}$. Como hemos señalado, a partir de nuestro trabajo de campo constatamos que las imágenes veneradas en el contexto de las fiestas religiosas operan de esta manera, como si fueran personas, convirtiéndose en interlocutoras en el proceso de

18 'El proyecto de la 'estética indígena' está, en esencia, orientado a refinar y expandir la sensibilidad estética del público occidental al proporcionar un contexto cultural en que los objetos de arte no occidentales pueden asimilarse a las categorías de valoración artístico-estética de Occidente" (Gell, 2016, p. 33). Para Gell, si bien toda teoría del arte tiene como fundamento la idea de agencia, la teoría "estética" se centra en lo que la filosofia occidental denomina el "juicio estético" (se concentra, podríamos decir, en la agencia intelectual de los individuos). Para nosotros, por el contrario, la agencia es estética por naturaleza, no en un sentido normativo sino en el sentido "mimético-descriptivo" que hemos expuesto, entendiendo que no hay agencia sin performance.

${ }^{19}$ Este modo de significar no es exclusivo de la fiesta religiosa, pero sí es un modo que la caracteriza y que termina conformando la base para el desarrollo de una determinada peculiaridad cultural (a este respecto, véase la relación entre "estilo" y “cultura" en Gell 2016, pp. 201-210).

${ }^{20}$ A este respecto, véase el concepto de "experiencia estética" en Tatarkiewicz (2016, pp. 353-392).

${ }^{21}$ Es importante señalar que esta idea de la "agencia" de las cosas problematizada por el enfoque de la New Material Culture no es ajena a las culturas prehispánicas: por ejemplo, el caso de las "huacas" en el mundo inca (Allen, 2015). Rodolfo Kusch (1976), por medio del concepto de "geocultura", saca a la luz como aspecto fundamental de la cultura latinoamericana lo que podríamos llamar la "agencia del territorio" (montañas, ríos, valles), elemento muy enraizado en las cosmovisiones indígenas de nuestro continente. La vinculación de nuestro planteamiento con las cosmovisiones de los pueblos originarios es una tarea pendiente que, por lo demás, marca uno de los límites de nuestra reflexión.

74 | Alpha № 53 (Diciembre 2021) PÁGS. 65-88. ISSN 07 16-4254 
significación de la experiencia de fe que en ese contexto tiene lugar. Las imágenes comunican -revelan- algo que no depende solo de nuestra interpretación, sino de lo que ellas "quieran" comunicar en relación con una determinada comunidad histórica. Es por esta personificación de lo sagrado que se constata en la imagen material que el modo de significar esta experiencia, junto con estético, es también sacramental.

\section{LA LÓGICA ESTÉTICO-SACRAMENTAL}

Como hemos adelantado, entendemos el término "lógica", en un sentido amplio, como "modo de significar". Existen diferentes formas de significar. Así, se habla, por ejemplo, de una "lógica simbólica", que significa mediante fórmulas, números o símbolos. Ahora bien, el término lógica también alude a la coherencia interna de los modos discursivos $\mathrm{y}$, por tanto, a su validez epistemológica. Al hablar de una lógica estético-sacramental nos referimos a un modo de significar por medio de la producción y recepción de determinados objetos (icónicos) y prácticas (festivas), que es inseparable de la experiencia sensorial, que tiene sus propias reglas -su propia lógica y su propio alcance epistemológico-, y que da lugar a un tipo de conocimiento específico: el conocimiento de lo sagrado.

No vemos en esto una contraposición entre "rito" y "palabra" (Morandé, 2010) o una disociación entre fe y razón. En este sentido, la producción de significados jamás se ha restringido al ámbito de una "lógica formal", a una correspondencia exacta entre significante y significado, y mucho menos en el caso de la experiencia de lo sagrado, donde dicha correspondencia es imposible y en la que existe una interdependencia entre lo que se dice creer y lo que se hace (Morgan, 2018). Es en este sentido que empleamos, también de manera lata, el adjetivo "sacramental", aludiendo al carácter revelatorio que asume la participación en la performance celebrativa $(F R, 13)^{22}$. Como puntualiza Benedicto XVI: “el mensaje cristiano no era solo 'informativo', sino 'performativo'. Eso significa que el Evangelio no es solo una comunicación de cosas que se pueden saber, sino una comunicación que comporta hechos y cambia la vida" (SS, 2).

En lo que sigue, pues, intentaremos avanzar en la definición de los conceptos de "fiesta" " "imagen" desde el enfoque de la New Material Culture, mediaciones que, como hemos apuntado, en el contexto de nuestra investigación cumplen una doble función: aluden, por una parte, al referente empírico de nuestra reflexión y, por otra, describen este modo de significar que hemos caracterizado como "estético-sacramental".

\footnotetext{
22 "Se debe aceptar que a la liturgia en un primer momento se accede por la experiencia; primero se celebra y luego entra el intelecto y la voluntad. La celebración litúrgica (signa sensibilia) es acción (ergon) que se expresa con gestos, con signos verbales y no verbales, con símbolos, con música, con movimiento corporal, con lugares y con espacios, con asamblea, con temporalidad, con épocas, en definitiva, con la popularidad del pueblo de Dios que celebra." (Guzmán, 2018, p. 487).
}

AlPHA No 53 (DiciEMBRe 2021) PÁGS. 65-88. ISSN 07 16-4254| 75 


\subsection{LA FIESTA RELIGIOSA COMO DISPOSITIVO DE ENCANTAMIENTO}

Todas las fiestas son diferentes: se desarrollan en tiempos, espacios y modos distintos; congregan comunidades diversas y concitan diversos grados de institucionalidad; en unas hay bailes y música, comida y bebida, competencias y juegos, mientras que otras se celebran sobriamente; unas son más seculares que otras ${ }^{23}$. La fiesta religiosa, no obstante, aun siendo heterogénea e incluso cuando ha sido institucionalizada o secularizada en algún grado, conserva dos dimensiones estructurales: constituye, por una parte, un tiempo de excepción -un tiempo de ruptura (Echeverría, 2011), regeneración (Bajtín, 2003), y metamorfosis (Cruz, 1995)- y, por otra, da lugar a la epifanía del objeto celebrado - en nuestros casos de estudio, la imagen de San Pedro, la Virgen y el Nazareno-. Este carácter extraordinario y portentoso de la fiesta, sin embargo, no nos debe conducir a la conclusión de que la fiesta es una farsa, sino todo lo contrario: es la piedra angular de la vida social de la comunidad que la celebra ${ }^{24}$.

La fiesta religiosa como fenómeno social, particularmente ostensible y vigente en nuestro continente, problematiza, sin negarlas, dos supuestas condiciones de posibilidad de la modernidad: la secularización y la estabilidad institucional. Si bien en el debate relacionado con la postmodernidad ya ha sido establecido que nunca existió una modernidad unívoca (García Canclini, 2001), y, en particular en Latinoamérica, se ha destacado que, por paradójico que parezca, la religión opera como catalizador de los procesos de modernización cultural (Parker, 1994 y Morandé, 1984), la modernidad sigue asociándose de forma implícita a una confianza ciega -incluso supersticiosa- en la infalibilidad de la razón instrumental y en la inmortalidad de las instituciones ${ }^{25}$. La fiesta religiosa, con su carácter disruptivo y extático, pone de relieve la fragilidad del orden institucional y las limitaciones del racionalismo, insistimos, sin clausurarlos.

Como se ha señalado, lo festivo es una dimensión de la existencia y, en este sentido, ensancha los límites de lo real, vuelve fluida la frontera con lo imaginario y lo

\footnotetext{
${ }^{23}$ Por ejemplo, la fiesta de San Pedro en Caleta Portales asume un carácter más bien cívico en el que se celebra la identidad del pescador, desarrollándose en encuentros puntuales en la caleta entre los mismos pescadores, mientras que la fiesta de la Virgen de la Tirana es masiva y, por medio del baile y la música ininterrumpida día y noche, construye un espacio y un tiempo autónomo que conduce a un estado de trance colectivo; por su parte, la fiesta del Nazareno de Caguach se realiza en una isla remota, y celebra, entre otras cosas, la hermandad de las comunidades huilliches de las islas vecinas con una regata.

${ }^{24}$ Todas las fiestas comportan ciertos actos complementarios asociados a su organización (eventos de financiamiento, ensayos, constitución de comités, etc.), los que se desarrollan durante todo el año, dando continuidad e identidad a las relaciones de la comunidad celebrante. En este sentido, hay que distinguir entre la fiesta como elemento constitutivo, diacrónico, de la vida social, y la celebración de la misma como su momento sincrónico. Si bien la fiesta se celebra "una vez", sigue operando todo el año.

${ }^{25}$ Se hace irresistible ejemplificar la vigencia de la superstición ilustrada con las columnas de opinión del rector Carlos Peña sobre del estallido social en Chile, cuyos planteamientos dieron lugar al libro Pensar el malestar. 76 | AlpHA № 53 (DiciEMBRE 2021) PÁGS. 65-88. ISSN 07 16-4254
} 
hace eficaz. Ante el supuesto desencantamiento del mundo que resultaría de la modernidad, las fiestas, y en especial las religiosas, siguen operando como una forma de encantamiento de la realidad, en la que irrumpe de manera verosímil -se revela- la presencia de lo sagrado ${ }^{26}$. El término "encantamiento" ha sido bastante productivo en el contexto de la discusión estética contemporánea, situándose su origen en la teoría estética de la antigüedad griega (Tatarkiewicz, 2016, pp. 357-358).

El encantamiento vendría a describir el estado de fascinación, arrebato y enajenación que produciría la experiencia estética -como también la experiencia erótica o la experiencia de lo sagrado-, lo que no se identificaría con un mero estado de intemperancia o irracionalidad, sino que constituiría la base que hace posibles experiencias de esta naturaleza. Así, al referirse a las virtudes éticas, Aristóteles destaca que el encantamiento del arte no tiene relación con una falta de sensatez, prudencia o moderación: ni aquellos que se deleitan con las cosas bellas ni el ocurrente Ulises, que se las arregla de forma ingeniosa para escuchar el canto de las sirenas, podrían ser caracterizados como intemperantes (Ética a Eudemo $1230 \mathrm{~b} 31)^{27}$.

Haciendo alusión a su etimología asociada al efecto de posesión que ejerce la música en quien la escucha, el encantamiento ha sido ilustrado con el episodio de las sirenas (Odisea XII), cuyo canto hacía olvidar toda responsabilidad, objetivo o plan, quedando prendado quien las escuchaba a un placer engañoso y destructor. Entre las hazañas de Ulises se cuenta el haber escuchado el canto de las sirenas sin haber sucumbido a su hechizo, pudiendo disfrutarlo y continuar su viaje de regreso a Itaca ${ }^{28}$. Ahora bien, más allá de su potencial enajenador, el encantamiento, en primer término, hace referencia a la misma condición de posibilidad de la aisthesis o experiencia sensible: la prevalencia de los sentidos en el proceso semiótico que desencadena la cognición. Dicho de otro modo: dejarse impactar por la energía propia del color, el sonido, o el movimiento, antes de encasillarlos en un determinado significado. Esta condición de posibilidad de la experiencia estética es descrita a su vez con el concepto de "prendamiento estético":

\footnotetext{
${ }^{26}$ Moderns tends to think of enchantment as something that resists science and reason, which way be why discussion of modernity has long invoked the countervailing idea of disenchantment. As described by a range of social analysts such as Max Weber, Talcott Parsons, Peter Berger, Jürgen Habermas, Stephen Toulmin, and Charles Taylor, modernity stresses rationality as a principal feature of what sets moderns apart in the entire history of the human species (Morgan, 2018, p. 8).

${ }^{27}$ En este mismo sentido, la mímesis es el modo en que los niños adquieren sus primeros aprendizajes, imitando, pero también es la manera en que el ciudadano, mediante la catarsis, pasa de la ignorancia al conocimiento de las virtudes ciudadanas (Poética 1449 b). A este respecto también es oportuno destacar la concepción sofista

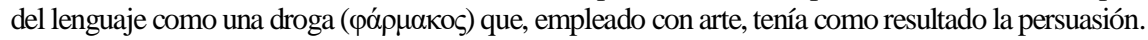

${ }^{28}$ Otros relatos que ejemplifican el estado de encantamiento son el episodio del baile de Salomé ante el rey Herodes, el autoencantamiento de Narciso frente a su reflejo, o el amor de Pigmalión por Galatea, la estatua de su autoría que por último Afrodita, conmovida, convierte en mujer de carne y hueso (Morgan, 2018, pp. 1-2, 21).
} 
prendamiento -derivado de la experiencia corporal del crío al prendarse del pezón de la madre-como origen y modelo de la condición de estesis. Lo que hace posible el prendamiento es esa afinidad morfológica íntima entre el sujeto y el objeto. Tal acoplamiento en forma y sustancia entre la concavidad de la boca de un mamífero y la convexidad del pezón de la madre permite la adherencia. [...] En el acto de prendamiento, el sujeto se acopla a la forma de su objeto a través de diversos registros de la experiencia -visual, acústico, corporal o verbal- y se adhiere a la reticulación semiósica que va generando a partir de tal objeto [...] "prendamiento" implica fascinación, seducción, ímpetu, nutrición y apetencia, más afines al fenómeno que nos ocupa" (Mandoki, 2006, pp. 68-69).

Ahora bien, es importante distinguir el encantamiento, en tanto que categoría estética, respecto de otros conceptos como la magia, la idolatría, o el animismo, que se han empleado normativamente para subrayar los límites de una determinada ortodoxia religiosa o epistemológica ${ }^{29}$. En este sentido, el encantamiento es experimentado por chamanes, artistas y científicos y, más que dar cuenta de un comportamiento extravagante, destaca la dimensión estética del conocimiento, relativizando la supuesta supremacía epistemológica de las ciencias positivas, tal como ha sido concebida por la epistemología moderna. El encantamiento es un poder, atribuible de igual modo a personas y cosas, que atrae y posee, razón por la que también produce rechazo, dado que no se puede controlar del todo ${ }^{30}$. Es por esto que los/as clérigos/as de la modernidad buscaron de forma desesperada censurar y controlar este tipo de experiencias -recordemos la condena republicana de las fiestas religiosas (Cruz, 1995)-, despojándolas, además, de su estatuto epistemológico ${ }^{31}$.

\footnotetext{
${ }^{29}$ Enchantment may be said to precede religion, magic, science and art. But as soon as I say that, it becomes necessary to avoid confusion with Edward Tylor's famous claim that the essence of religious is animism. I argue that enchantment consist of a metamorphosis of one thing into another, and that animism is only one instance of this [...] And it is well worth pointing out that the need to differentiate enchantment from religion, magic, and science is often pressed and enforced by ideological interests. Theologians, scientists, and scholars alike often do this, proclaiming a behavior to be "superstitious", "idolatrous", or "magical" when it violates one notion or another that is sacred to their respective guilds. (Morgan, 2018, p. 11).

${ }^{30}$ To be enchanted means to lose control at the hands of a device or feeling or experience that places one in the service of another (Morgan, 2018, p. 3).

${ }^{31}$ Pese todo, la ciencia y la técnica también tienen una dimensión "encantadora": Thus, the appearance of new media and technologies in nineteenth-century Europe and America elicited a host of exclamations concerning their revelatory, mysterious powers. Telegraphy became a primary metaphor for spiritualism; photography captured the soul and documented spiritual effluvia; the phonograph recorded the sounds of the dead. Electricity was miraculous, and magnetism was a soul-curative. (Morgan, 2018, p. 7). Véase tb. Those who would disenchant for religious, political, or rationalistic reasons assert these critiques, but not without indulging their own forms of counterenchantment, whether it is the true religion, the authentic political leader, or something called good science (Morgan, 2018, p. 4).

78 | Alpha № 53 (Diciembre 2021) PÁGS. 65-88. ISSN 07 16-4254
} 
Cabe notar el paralelismo del encantamiento con el concepto de juego planteado por Gadamer (1991, pp. 66-84), en el que se destaca la razonabilidad necesaria para que este se desarrolle. Por una parte, el juego exige entregarse, dejarse encantar o prendarse por él; sin embargo, por otra parte, el juego produce un orden y determinados roles, que son razonables, pues de lo contrario serían inverosímiles, pero que al mismo tiempo son lo suficientemente flexibles para que cada participante pueda jugar a su manera ${ }^{32}$. En el juego se puede ser, de verdad, árbol, casa o dios, yo puedo ser tú y tú puedes ser yo. En este sentido, el juego haría comparecer el mundo como un espacio de encantamiento, que se puede conocer porque tiene reglas, pero donde esas reglas no se pueden objetivar del todo porque cada vez es interpretado por un determinado jugador que tiene algo propio que aportar, en un espacio y un tiempo concretos:

Las reglas e instrucciones que prescriben el cumplimiento del espacio lúdico constituyen la esencia de un juego. $Y$ esto vale en toda su generalidad siempre que haya alguna clase de juego [...] El juego humano requiere su propio espacio de juego. La demarcación del campo de juego - igual que la del ámbito sagrado, como destaca con razón Huizinga- opone, sin transición ni mediaciones, el mundo del juego, como un mundo cerrado, al mundo de los objetivos" (Gadamer, 1999, p. 150).

La fiesta religiosa, al igual que el juego, también opera como un dispositivo de encantamiento, es decir, como la producción de las condiciones materiales necesarias para que la experiencia estética del encantamiento tenga lugar ${ }^{33}$. No obstante, a diferencia del juego, la fiesta adopta una dimensión institucional de la que el juego carece, y que en muchos casos desafía el orden establecido: la sociedad de baile, la cofradía, el sindicato, el cabildo ${ }^{34}$. Así, en las fiestas religiosas se ocupa -se reivindica- un espacio público y un tiempo social que, en virtud de ciertas operaciones artísticas como decorar, engalanar, bailar, teatralizar, etc., dan lugar a la comparecencia eficaz de lo sagrado, incidiendo de este modo en la vida de las personas ${ }^{35}$. En las fiestas religiosas que hemos estudiado,

\footnotetext{
32 El relato mítico es definido por Aristóteles (Poética 1450 b) como "orden de cosas o acontecimientos"

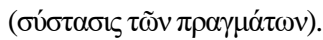

33 "La fiesta se juega, es decir, se lleva a cabo en una representación, dentro de un campo propio, en particular delimitado como festivo, como acción identificadora, dramatizada o competitiva. Los que participan en el culto festivo procuran un orden de las cosas, una figuración superior al orden de la vida diaria. En sus aspectos formales, esta representación exhibe también los caracteres del juego" (Cruz, 1995, p. 20).

${ }^{34}$ En nuestro trabajo de campo pudimos constatar la tensión existente entre este tipo de organizaciones de base respecto de las autoridades civiles y eclesiásticas. En el fondo, se trata de una lucha por el control de aquel poder, social y religioso, de lo sagrado. Consideramos que esta tensión, esta "resistencia simbólica" (Parker 1994) característica de la denominada "religión popular", se ve reflejada de manera paradigmática en la dinámica espacial de la procesión, momento central de la fiesta religiosa: la imagen (lo sagrado) es literalmente raptada desde el templo (espacio de control) por una multitud, que la conduce por la plaza y las calles, apropiándose de ella y comunicándose, sin intermediarios, con ella.

${ }^{35}$ En este sentido, el arte sería una “tecnología del encantamiento" (Gell, 2016, pp. 105-136).
} 
como se ha destacado, todas estas acciones giran en torno a un objeto concreto, la imagen de culto, cuya presencia física constituye el epicentro del evento festivo.

En esta línea, el enfoque de la New Material Culture destaca el rol fundamental que juegan las imágenes, desde su condición material, como foco de encantamiento ${ }^{36}$. En el contexto de la fiesta que se celebra en su honor, la imagen de yeso o madera, vestida y adornada, no comparece ni como símbolo ni como ídolo sino como el índice de una agencia sacramental, es decir, como la fuente de la que emana el poder transformador del prototipo sagrado ${ }^{37}$. Ahora bien, las imágenes no actúan solas, como máquinas, sino como personas, mediante relaciones interpersonales con las personas que participan de la fiesta $^{38}$. Por esta razón, la imagen de culto no existe -al menos no como persona- sin la fiesta, es decir, sin todas aquellas acciones de los celebrantes que conforman el acto festivo, dando lugar a una trama de relaciones que tienen un efecto de largo plazo en la vida de la comunidad, más allá del momento celebrativo (Morgan, 2018, p. 19).

\subsection{LA AGENCIA SACRAMENTAL DE LA IMAGEN ${ }^{39}$}

Al igual que las fiestas, todas las imágenes son diferentes: unas son bidimensionales, otras de bulto; unas de madera, otras de fibra de vidrio; unas móviles, otras fijas; unas bonitas y otras feas. Todas las imágenes celebradas en las fiestas religiosas, no obstante, comparten dos características asociadas a su agencia sacramental: por una parte, cada una está vinculada a un prototipo histórico, a una persona concreta de la historia sagrada que confiere una determinada personalidad a cada imagen (maternidad, liderazgo, compañerismo, etc.) y, por otra, dicho prototipo actúa en el índice

\footnotetext{
${ }^{36}$ Enchantment always has something to do with some form of representation - dreams, fantasies, delusions, pictures, icons, cult figures, songs, dances, poems - and with the powerful effect they exert over the devotees who craft and adore them [...] The enchantment relation with the beloved is not a departure from reality but, instead, the pivotal point around which the lover's world has come to turn. That relation is sacralized by the image of it when the image (or song or poem or token) evokes the beloved, delivers to him or her the impassioned longing of the lover, stokes the lover's desire, embodies their love as a gift from one to the other (Morgan, 2018, p. 15).

${ }^{37}$ El Santo Ícono constituye una presencia activa y salvífica de Jesucristo mismo, de la Santísima Virgen o de los Santos en Gloria para el feligrés que les rinde culto: orando u ofrendándose el homenaje de su vela o incienso. Esto quiere decir que el culto al Santo Ícono tiene una estructura sacramental. Es por eso que Theodoro de Studion, Damasceno, el Areopaguita y otros Doctores de la Iglesia llaman el Santo Ícono: "Mysterium", o "Sacramentum" (Van Kessel, 2006, p. 67).

${ }^{38}$ En este sentido, como ya hemos subrayado: a simple subject/object distinction of human and thing is misleading. The power of images is better understood in terms of networks that include images and viewers and several other actors, both human and nonhuman (Morgan, 2018, p. 4). De la descripción de la imagen como agente en el marco de nuestro estudio de casos véase Aguirre (2020ª pp. 198-202).

${ }^{39}$ Acerca de la aplicación de la teoría de la agencia en el marco de nuestra investigación, véase Aguirre (2020a , pp.176-181).

80 | Alpha № 53 (Diciembre 2021) PÁGS. 65-88. ISSN 07 16-4254
} 
-el objeto material-, el que reproduce en su verosimilitud el tipo iconográfico de aquella persona histórica, es decir, el conjunto de rasgos que configura su aspecto.

Ahora bien, el tipo iconográfico, a diferencia de una fotografía, no busca parecerse al prototipo "naturalmente" sino "existencialmente", dejando un margen de variabilidad bastante amplio para el desarrollo de diferentes estilos y soportes, así como para la participación de toda la comunidad en la caracterización de la imagen. En este sentido, el índice no pretende identificarse con el prototipo, sino solo asemejarse a él, permitiendo que este se vaya enriqueciendo mediante advocaciones y expresiones regionales, es decir, a partir de su relación con una determinada comunidad histórica que participa de manera activa en la performance sacramental ${ }^{40}$. Basados en esto, podríamos decir que la imagen posee una "personalidad distribuida" (Gell, 2016, pp. 137-200) entre el índice (el objeto material) y su prototipo (la persona histórica que representa), los cuales se encuentran vinculados existencialmente a través del aspecto ${ }^{41}$. Dicho de otro modo, la biografía del santo se sigue escribiendo-abduciendo-a partir de su relación con las personas:

Si la observamos desde esta perspectiva, la persona y la mente no se confinan a unas coordenadas espaciotemporales, sino que consisten en un abanico de sucesos biográficos y los recuerdos que generan, además de una categoría variada de objetos, rastros y restos materiales que se pueden atribuir al individuo. Estos, en conjunto, testimonian la agencia y el ser paciente durante una extensión biográfica que, de hecho, puede prolongarse mucho más allá de la muerte biológica. De esta manera, se comprende a la persona como la suma de los índices que demuestran, no solo en vida, la existencia biográfica de aquella. La agencia personal, como intervención en el entorno causal, crea un "objeto distribuido", es decir, todas las diferencias materiales del "modo en que son las cosas", de las que se pueden abducir una agencia particular (Gell, 2016, p. 275).

Como se pone de relieve desde el enfoque de la New Material Culture, la atribución de intencionalidad a un objeto inerte como una imagen de madera es un fenómeno mucho más habitual de lo que podemos imaginar. Gell lo describe como aquellas situaciones en las que los objetos materiales suscitan una operación cognitiva definida como "abducción de la agencia" (p. 44) ${ }^{42}$. De este modo, la abducción consistiría

\footnotetext{
${ }^{40}$ Sobre la dimensión “popular” del sacramento, véase SC 26 y Guzmán 2018: 495. Para una descripción de esta relación entre imagen y comunidad, véase nuestro estudio de casos en Aguirre (2020a , pp. 183-198).

${ }^{41}$ Este es justamente el corazón de la argumentación teológica que justifica la dimensión sacramental de las imágenes en el cristianismo, cuyo fundamento último proviene del acontecimiento de la Encarnación: la unión hipostática de la naturaleza divina y la naturaleza humana en la persona de Jesucristo, que es “imagen” (દikóv) del Padre (Aguirre, 2018b, pp. 251-272).

${ }^{42}$ Gell toma el término de la teoría semiótica de Ch. S. Pierce. Sin embargo, este fue acuñado en un principio

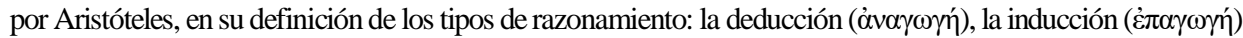

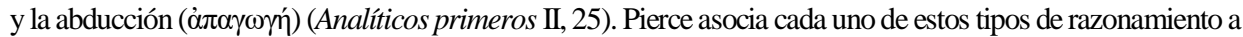
diferentes áreas del conocimiento: la filosofía, la ciencia, y el arte, respectivamente (Pierce, 1986, pp. 41-62).
} 
en la inferencia causal que solemos hacer ante situaciones como el humo que sale por debajo de la puerta o la sonrisa de un/a desconocido/a en un ascensor. En ambos casos, sin tener todos los elementos para corroborarlo, procedemos a elaborar una hipótesis razonable: "hay un incendio" o "esta persona me está coqueteando". De manera análoga, a la persona distribuida del santo que comparece en la imagen se atribuyen acciones portentosas que pueden parecernos más o menos inverosímiles, pero que en ningún caso debemos descartar como irracionales, pues dan cuenta del complejo proceso de producción de un imaginario colectivo que determina formas de relación, incide en las dinámicas sociales y, en último término, informa acerca de un determinado sentido de la $\mathrm{fe}^{43}$.

A diferencia del concepto, asociado a operaciones lógicas como la inducción o la deducción, la imagen da lugar a un razonamiento abductivo que, como se ha destacado, es inseparable de la actualidad de la experiencia sensible. De este modo, acciones como tocar, besar, o vestir una imagen de culto -en definitiva, relacionarse con ella como si fuera una persona- van configurando una retícula significativa en donde también se atribuyen acciones a la imagen y se abduce la agencia sacramental del prototipo. En este sentido, la abducción "esboza la apertura a una semiosis infinita de sentidos sobre la experiencia de Dios" (Cárdenas, 2014, p. 366). Tal como en un juego, que da lugar a un régimen autónomo de causalidad, es imprescindible involucrarse en la dinámica estética de lo sagrado para llegar a abducir su significado ${ }^{44}$.

Ahora bien, este rol fundamental que asume la experiencia sensible en los procesos de razonamiento abductivo no debe traducirse en una supresión del rol que juega la

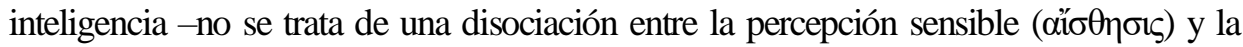
intelección (vónбı), entre la estesis y la semiosis (Mandoki, 2006)-, sino que relativiza la definición moderna del conocimiento como representación mental y pone de manifiesto la inherencia de todo proceso cognitivo respecto de lo material y lo corporal ${ }^{45}$. Dicho de otro modo, la abstracción propia del proceso cognitivo es un camino de dos direcciones entre el continuum de lo sensible y lo inteligible, en el que no se reconoce una superioridad epistemológica en ninguno de estos planos y donde los límites entre sujeto y objeto se

\footnotetext{
${ }^{43}$ Véase: "El contexto y el sentido común no son artefactos residuales que se puedan eliminar de manera progresiva mediante el descubrimiento de reglas más elaboradas. Constituyen la esencia misma de la cognición creativa" (Varela, 2005, p. 95). Respecto de la comprensión del "milagro" como unidad de sentido más que como hecho extravagante, véase Bentué (2015, pp. 195-204).

44 "El placer lúdico consiste en esto precisamente: en la experiencia de la imposibilidad de establecer si un hecho dado debe su presencia a una concatenación causal de otros hechos anteriores (la preparación de un deportista, el conocimiento de un apostador, por ejemplo) o justo al contrario, a la ruptura de esa concatenación causal (la "mala suerte" del contrincante, la "voluntad de Dios")." (Echeverría, 2011, p. 190).

45 "Los fenomenólogos se han explayado explicando por qué el conocimiento se relaciona con el hecho de estar en un mundo que resulta inseparable de nuestro cuerpo, nuestro lenguaje y nuestra historia social"'(Varela, 2005, p. 95).

82 | Alpha No 53 (Diciembre 2021) PÁGS. 65-88. ISSN 07 16-4254
} 
desdibujan ${ }^{46}$. En este sentido, como pone de relieve el destacado neurobiólogo chileno Francisco Varela (2005), el conocimiento es el resultado de un proceso dinámico en el que tanto el sujeto como el objeto de la cognición se constituyen de manera simultánea:

El verdadero desafío que esta orientación plantea a las CTC [Ciencias y Tecnologías de la Cognición] es que pone en tela de juicio el supuesto más arraigado de nuestra tradición científica: que el mundo tal como lo experimentamos es independiente de quien lo conoce. En cambio, si estamos obligados a concluir que la cognición no se puede entender adecuadamente sin sentido común, el cual no es otra cosa que nuestra historia corporal y social, la inevitable conclusión es que conocedor y conocido, sujeto y objeto, se determinan uno al otro y surgen simultáneamente (Varela, 2005 p. 96). ${ }^{47}$

La fiesta religiosa otorga el medio espacio-temporal para la epifanía sensible de aquella persona distribuida del santo, que se manifiesta por medio de milagros y muchas otras acciones que denotan una intencionalidad propia de la imagen, superando, en alguna medida, toda reducción semiótica (Gell, 2016, pp. 45-46) ${ }^{48}$. Ahora bien, como indicamos más arriba, la imagen de culto no busca reemplazar a la persona que representa, pero sí reivindica una vinculación existencial con ella, es decir, que la persona representada actúa sacramentalmente en la imagen y mediante ella su existencia se vincula con la existencia de la persona creyente. En este sentido, como ya hemos destacado, la imagen de culto no funciona ni como ídolo -identificación entre índice y prototipo- ni como símbolo, -distinción categórica entre significante y significado-, sino como "ícono" (घikív). Dicho de otro modo, la imagen, en este caso, no funciona solo semióticamente sino, en primer término, opera sacramentalmente.

En el contexto del cristianismo, el sacramento constituye justamente una manera de significar la relación de Dios con el pueblo creyente, cuya significación no se limita a un plano meramente conceptual, sino que, como hemos señalado, opera performativamente. El sacramento en el cristianismo, que encuentra su fundamento último en el acontecimiento de la Encarnación, significa la irrupción de lo divino en lo humano, transfigurándolo. En este sentido, la imagen de culto funciona como un signo

\footnotetext{
${ }^{46}$ Este camino de dos direcciones, en el contexto del Barroco, se recorre mediante la imagen, que posee una doble naturaleza: "mitad cuerpo y mitad concepto" (Martínez, 2011, pp. 167-169).

${ }^{47}$ Varela explica este carácter performativo del conocimiento con el término "enacción": "Lo que marca la diferencia entre el enfoque enactivo y cualquier forma de contructivismo o neokantianismo biológico es este énfasis en la codeterminación (del huevo y la gallina)" (p. 102). Véase tb. la noción de "mente extendida" en la teoría de la agencia (Gell, 2016, pp. 273-313).

48 "En Caguach el Nazareno cambia el aspecto de su rostro vaticinando que algo sucederá; en Tirana la Chinita expresa su disconformidad respecto al modo en que es acicalada; incluso el San Pedro de los pescadores, cuya efigie pasa a un segundo plano en el marco de una celebración de carácter más recreativo, para esta ocasión no se le pinta, como si fuera un objeto manipulable a discreción, sino que se le 'viste' y se le saluda en forma respetuosa en el día a día de la Caleta" (Aguirre, 2020ª, p. 199).
} 
sensible - un índice- que no solo significa, sino que también realiza la divinización del hombre (SC 7).

La fiesta religiosa, entendida como el medio en el que se despliega la agencia sacramental de la imagen, también tiene un carácter sacramental ${ }^{49}$. En este sentido, en el contexto de las fiestas religiosas que hemos estudiado, la fiesta y la imagen son realidades interconectadas: del mismo modo que la imagen opera festivamente al suscitar ciertas acciones constitutivas del complejo y multidimensional orden festivo, la fiesta opera desde lo icónico al constituirse en la mediación matérico-sensorial -el dispositivo de encantamiento-donde se despliega la agencia sacramental del santo en la imagen. Como hemos destacado, esta dimensión sacramental de la imagen que suscita la fiesta encuentra, en el caso del cristianismo, una sólida fundamentación teológica que se remonta a la denominada querella iconoclasta ${ }^{50}$.

La exposición detallada de los fundamentos teológicos de la veneración de las imágenes en la tradición cristiana y su relación con las fiestas religiosas que hemos estudiado será abordada en una futura publicación. Por ahora nos interesa subrayar la interdependencia entre lo festivo y lo icónico como rasgos característicos de este modo de significar que hemos denominado estético-sacramental. En otras palabras: la imagen de culto opera como persona gracias al encantamiento de la fiesta religiosa, transfiriendo de esta manera su eficacia sacramental a la vida del creyente.

Somos conscientes de que esta agencia de la imagen no adopta un sentido propiamente sacramental para todos los asistentes a una fiesta religiosa, del mismo modo que el agua puede no tener este sentido para algunos asistentes a un bautismo; sin embargo, el concepto teológico de "sacramento" podría describir lo que experimentan todos/as aquellos/as que reconocen en la imagen una intervención salvífica de Cristo, la Virgen o un santo ${ }^{51}$. Como destaca Gell (2016, p. 169), sea cual sea la explicación de lo

\footnotetext{
49 “Las fiestas son participación en el actuar de Dios en el tiempo, y las imágenes mismas, en cuanto memoria cristalizada, contribuyen a la actualización litúrgica” Ratzinger 2001, pp. 138-139.

50 "La cuestión dogmática que se establece en este periodo pasa por el hecho de que la semejanza representada en la imagen de culto pertenece a la persona representada, y si en realidad creemos que Dios se encarnó en la persona de Jesucristo (si creemos que el Hijo es imagen del Padre y que actúa a través de Él) debemos creer que Jesucristo se manifiesta en la expresión (charaktêr) de su imagen visual y que actúa kenóticamente a través de ella, no por obligación sino en virtud de un acto de donación y gratuidad. De este modo, como concluye el cardenal Schönborn, 'Dios ha tomado un rostro humano y dicho rostro es el lugar privilegiado de su revelación"' (Aguirre, 2020b, pp. 226-227).

${ }^{51}$ Tanto en la fiesta de la Virgen de la Tirana como en la fiesta del Nazareno de Caguach, que tienen un marcado componente mistagogógico, comparece con mayor claridad esta agencia sacramental en el sentido que hemos descrito, mientras que en la fiesta de San Pedro de Caleta Portales es menos evidente. En todos los casos, no obstante, los actores de las fiestas estudiadas se refieren a la imagen como "persona". Así, lo que nosotros llamamos "agencia sacramental", desde el enfoque de la New Material Culture se denomina "agencia 84 | Alpha № 53 (Diciembre 2021) PÁGS. 65-88. ISSN 07 16-4254
} 
que lo motiva, se venera una imagen porque en ella se reconoce la presencia de la divinidad. Ya hemos manifestado que nuestra intención no es definir algo así como una esencia cristiana de la fiesta religiosa en Latinoamérica, sino establecer un determinado punto de referencia teológico que, a nuestro parecer, no es inverosímil. En este sentido, definimos como "estético-sacramental" la lógica de la fiesta religiosa, pues intuimos que en ella "los signos sensibles significan y, cada uno a su manera, realizan la santificación del hombre" (SC 7).

\section{CONCLUSIONES}

Como señalamos al principio, el contenido del presente artículo se enmarca en el desarrollo de una investigación de tres años. El objetivo principal de esta investigación es desarrollar una reflexión teológico-fundamental de la denominada "religión popular", superando el enfoque pastoral-normativo que ha marcado la reflexión teológica respecto de este fenómeno constitutivo del cristianismo latinoamericano. La pregunta que origina nuestra investigación se podría formular de la siguiente manera ¿de qué manera y en qué sentido la "religión popular" se constituye en un "lugar teológico"? Al comenzar a abordar esta pregunta constatamos que el fenómeno en cuestión asume la mayoría de las veces una connotación negativa, conduciendo a esquemas de valoración binarios. En alguna medida, la "religión popular" aparecía como un "no lugar teológico".

De este modo, el primer paso de nuestra investigación se orientó a delimitar de manera empírica este lugar, reconociendo en la fiesta religiosa una muestra lo suficientemente paradigmática de aquellos objetos y prácticas que dan cuerpo a la "religión popular". El segundo paso consistió en definir categorías de análisis vinculadas a aquella realidad empírica, pero que a su vez pudieran servirnos de mediaciones conceptuales para desarrollar una reflexión teológico-fundamental. Estas categorías de análisis fueron los conceptos de "fiesta" e "imagen" que, en el contexto de nuestra investigación, operan como palabras-cosas inseparables de ciertos hechos concretos, pero que a su vez abren un horizonte hermenéutico.

Ahora bien, un paso fundamental para comprender en qué sentido este lugar trazado empíricamente se constituye en un "lugar teológico" es sobre todo la problematización del estatuto epistemológico de los modos de significar que allí entran en juego. Dicho de otro modo: establecer cómo se comunica la vida teologal que allí se desarrolla. Este fue el objetivo principal del presente artículo. Así, a partir de los conceptos "fiesta" e "imagen" intentamos configurar el horizonte estético-teológico de nuestra reflexión, denotando en estos términos, junto con la dimensión estética, la dimensión sacramental de los objetos y prácticas que constituyen la fiesta religiosa. A su vez, intentamos delinear el estatuto

religiosa", es decir, que las imágenes en contextos como el de la fiesta no actúan como símbolos ni retratos sino como "cuerpos artefactuales" (Gell, 2016, p. 140).

AlPHA No 53 (DiCIEMBRE 2021) PÁGS. 65-88. ISSN 07 16-4254| 85 
epistemológico del modo de significar estético-sacramental que caracteriza la fiesta religiosa. El siguiente y último paso de nuestra investigación será profundizar en la definición teológica de esta lógica estético-sacramental que hemos descrito aquí.

Sin temor a equivocarnos, no obstante, podemos adelantar que la "religión popular" es un aspecto de la religión, no su contraparte. De manera análoga, la fiesta religiosa constituye un aspecto, fundamental, de la Iglesia latinoamericana. Es uno de sus atrios, no el patio de atrás. En este sentido, la naturaleza festiva e icónica de la fe del Pueblo de Dios que peregrina por estas latitudes no constituye, como se ha insinuado muchas veces, un obstáculo para el conocimiento de Dios sino, por el contrario, se encuentra enraizada en el hecho fundamental de la revelación cristiana: el hecho de que Dios mismo haya asumido una existencia corporal, haya puesto su tienda para celebrar con todos nosotros y nosotras, y que, en definitiva, se revele como "imagen visible del Dios invisible".

Trabajo realizado en el marco del Proyecto Fondecyt Iniciación $\mathrm{n}^{\circ}$ 11170285 (2017-2020): "Fundamentos estético-teológicos de la piedad popular". Proyecto para una reseña del proyecto vid. Aguirre 2018a.

\section{OBRAS CITADAS}

Aguirre, Federico (2020a). Religión popular: fiesta e imagen. Veritas 169-205.

_ (2020b). Tradición y transmisión de la fe. El caso de la religiosidad popular en el Chile actual. Scripta Theologica 52/1, 215-243.

— (2018a). Fundamentos estético-teológicos de la piedad popular. Proyecto Fondecyt Iniciación n ${ }^{\circ} 11170285$. Investigador responsable: Federico Aguirre". Teología y Vida 59/1, 155-159.

_ (2018b). Arte y teología. El renacimiento de la pintura de íconos en Grecia moderna. Ediciones UC.

Allen, Catherine (2015). The Whole World Is Watching: New Perspectives on Andean Animism. En Tamara Bray (Ed.), The archeology of Wak'as. Explorations of the Sacred in the Pre-Columbian Andes. (pp. 23-46). University Press,

Bajtin, Mijail (2003). La cultura popular en la Edad Media y el Renacimiento. El contexto de Françoise Rabelais. Alianza.

Bentué, Antonio (2015). La opción creyente. San Pablo.

Bergmann, Sigurd (2014). In the Beginning is the Icon. A Liberative Theology of Images, Visual Arts and Culture. Routledge.

Brown, Peter (2018). El culto a los santos. Sígueme. 
Cárdenas, Felipe (2014). Signos de la teología mística de la iglesia de oriente. Vladimir Lossky a la luz de la teoría semiótica de Charles Sanders Peirce. Theologica Xaveriana 64 / 178, 353-391.

Cruz, Isabel (1995). La fiesta: metamorfosis de lo cotidiano. Ediciones UC.

Cullen, Carlos (1981). El ethos barroco. Ensayo de definición de la cultura latinoamericana a través de un concepto sapiencial. En Racionalidad técnica y cultura latinoamericana. Ponencias y comunicaciones. Tercer Seminario Internacional Interdisciplinar de Intercambio Cultural Alemán-Latinoamericano. (pp. 10-36). Santiago de Chile,

Espinosa, Carlos (2012). "El barroco y Bolívar Echeverría: encuentros y desencuentros". Íconos 43: 65-80.

Gadamer, Hans Georg (1999). Verdad y método II. Sígueme.

(1991). La actualidad de lo bello. Paidós

García Canclini, Néstor (2001). Culturas híbridas. Estrategias para entrar y salir de la modernidad. Paidós.

Gell, Alfred (2016). Arte y agencia. Sb.

Guzmán, Gonzalo (2018). Re-pensar el ex opere operato. Una consecuencia necesaria de la naturaleza popular de la liturgia. Teología y vida 59/4: 481-502.

Isambert, Françoise-André (1982). Le sens du sacré. Fête et religion populaire. Ed. du Minuit.

Johansson, Cristián (1990). Religiosidad popular entre Medellín y Puebla: antecedentes $y$ desarrollo. Universidad Católica.

Martínez, Luz Ángela (2011). Barroco y neobarroco: del descentramiento del mundo a la carnavalización del enigma. Ed. Universitaria.

Morandé, Pedro (2010). Ritual y palabra. IES.

_ (1986). "Religiosidad popular como contracultura de la llustración". Nexo 7: 14-26.

- (1984). Cultura y modernización en América Latina. Encuentro.

Morgan, David (2018). Images at Work: The Material Culture of Enchantment. Oxford university Press.

Parker, Cristián (1994). Otra lógica en América Latina. Religión popular y modernización capitalista. FCE.

Peirce, Charles S. (1986). La ciencia de la semiótica. Nueva Visión.

Ratzinger, Joseph (2001). El espíritu de la liturgia. Una introducción. Cristiandad.

Ricoeur, Paul (2004). Tiempo y narración. Configuración del tiempo en el relato histórico. Siglo XXI.

Salinas, Maximiliano (2006). Para una teoría de la fiesta: la utopía del derecho a la vida abundante. En Fiestas tradicionales populares de Chile. (pp. 17-28). IPANC.

Sepúlveda, Fidel (2000). La fiesta ritual. Perspectiva estética y antropológica. Aisthesis 33: 3-29.

Tylor, Diana y Marcela Fuentes (ed.) (2011). Estudios avanzados de performance. FCE. 
Federico Aguirre

Van Kessel, Juan (2006). Los iconos de la Ortodoxia: diálogos con el más allá. Revista de Ciencias Sociales 16: 63-73.

Varela, Francisco (2005). Conocer. Las ciencias cognitivas: tendencias y perspectivas. Cartografía de las ideas actuales. Gedisa.

\section{DOCUMENTOS MAGISTERIALES}

EG Francisco, Exhortación Apostólica Evangelii gaudium, AAS 105 (2013) 1019-1137.

FR Juan Pablo II, Carta Encíclica Fides et ratio, AAS 91 (1999) 5-88.

SC Concilio Ecuménico Vaticano II. Sacrosanctum Concilium. Constitución sobre la Sagrada Liturgia, AAS 56 (1964) 97-134.

SS Benedicto XVI, Carta Encíclica Spe salvi, AAS 99 (2007) 985-1027. 